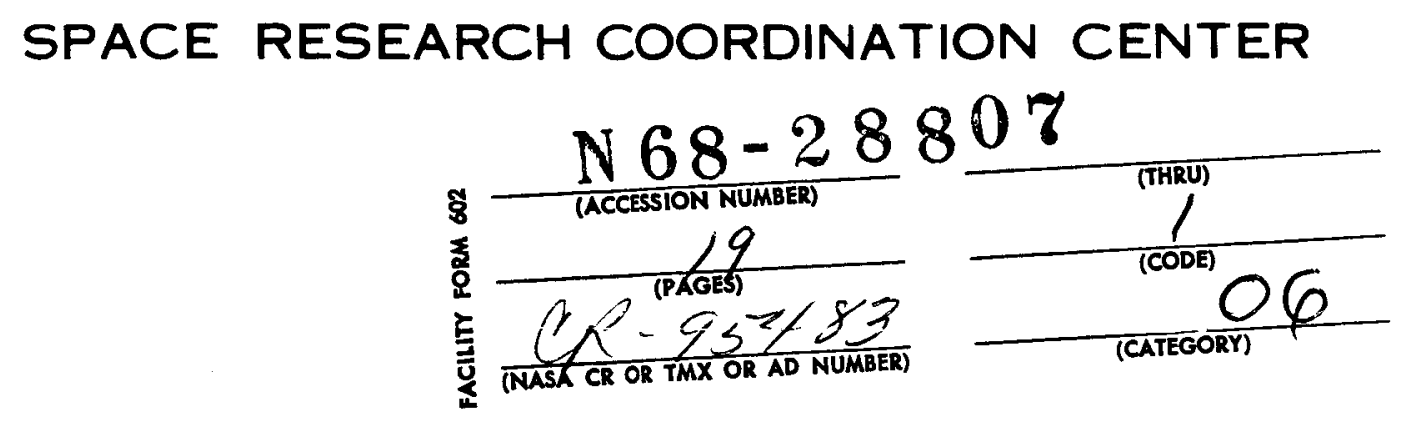

\title{
NEUTRAL REACTIONS INVOLVING \\ HYDROGEN AND OTHER MINOR CONSTITUENTS
}

\author{
BY \\ . FREDERICK KAUFMAN \\ DEPARTMENT OF CHEMISTRY
}

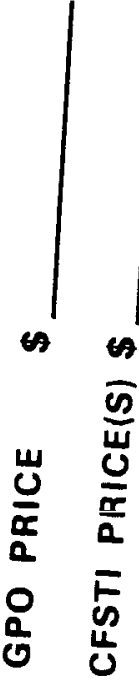

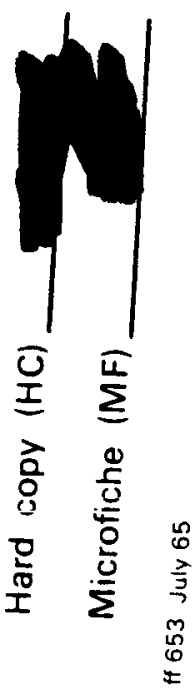

SRCC REPORT NO. 78

UNIVERSITY OF PITTSBURGH

PITTSBURGH, PENNSYLVANIA

8 JULY 1968 
The Space Research Coordination Center, established in May, 1963, has the following functions: (1) it administers predoctoral and postdoctoral fellowships in space-related science and engineering programs; (2) it makes available, on application and after review, allocations to assist new faculty members in the Division of the Natural Sciences and the School of Engineering to initiate research programs or to permit established faculty members to do preliminary work on research ideas of a novel character; (3) in the Division of the Natural Sciences it makes an annual allocation of funds to the interdisciplinary Laboratory for Atmospheric and Space Sciences; (4) in the School of Engineering it makes a similar allocation of funds to the Department of Metallurgical and Materials Engineering and to the program in Engineering Systems Management of the Department of Industrial Engineering; and (5) in concert with the University's Knowledge Availability Systems Center, it seeks to assist in the orderly transfer of new space-generated knowledgo in industrial application. The Center also issues pe riodic reports of space-oriented research and a comprehensive antual report.

The Center is supported by an Institutional Grant (N sG -416) from the National Aeronautics and Space Ad ministration, strongly supplemented by grants froth the A.W. Mellon Educational and Charitable Trust, the Maurice Falk Medical Fund, the Richard King Mellon Foundation and the Sarah Mellon Scaife Foundation. Much of the work described in SRCC reports is financed by ether grants, made to individual faculty members. 
Neutral Reactions Involving Hydrogen

and other Minor Constituents*

Frederick Kaufman

Department of Chemistry, University of Pittsburgh

Abstract

Experimental laboratory work is reviewed for the kinetics of 21 neutral, elementary reactions involving $\mathrm{H}, \mathrm{OH}, \mathrm{HO}_{2}, \mathrm{H}_{2}, \mathrm{CO}, \mathrm{N}_{2} \mathrm{O}, \mathrm{CH}_{4}$, and $\mathrm{Na}$.

\section{Introduction}

Five years ago, at the Berkeley Symposium, this author presented a review of laboratory studies of relevant neutral reactions involving hydrogen (1). The present paper will attempt to bring that review up to date, and it will also briefly discuss the reactions of certain other minor constituents, not previously covered, at the suggestion of the organizers of this Symposium. It will not present, specifically, work done at the author's laboratory, and so is likely to be a drab recitation of experimentally measured rate parameters. The seemingly chaotic diversity and corresponding lack of clear trends among such rate parameters is, of course, a consequence of the greater inherent complexity of neutral reactions whose cross sections are generally smaller, energy barriers larger, interactions weaker, and intermediate states less predictable than those involving electrons or ions. The lively progress of fundamental rate theory (2) during the last few years will in general not be reflected in this review. The day when the detailed course of most elementary reactions will be open to investigation by single-collision methods (e.g. crossed molecular beam) in addition to the varied arsenal of bulk methods (with increasing sophistication of specific quantum state analysis) is unfortunately

* This work was supported by the National Science Foundation under Grant GP-5369 and by the Defense Atomic Support Agency under Grant DA-ARO-D-31-124-G881 
not yet at hand - except for alkali atom reactions - but, hopefully, it is not far off. Until then, we must rely on chemical kinetic information obtained by various methods such as discharge-flow, flash photolysis, steady photolysis, high temperature kinetics and mechanism, flame sampling, shock-tube, and others. For the purpose of this l Symposium where the interest centers on reactions of simple atomic species at temperatures from about 200 to $1000^{\circ} \mathrm{K}$, the discharge-flow method has become the most widely used. Its many variants include formation of reactive species in glow discharges, in thermal sources, or by chemical reaction of energetic precursors; reaction with added molecules along a cylindrical flow tube or in stirred-flow reactor; and detection by measurement of a simply related chemiluminescent emission, by wire calorimetry, optical absorption, e.s.r. absorption, mass spectrometry, gas titration of the reactive species, or by other methods. As one reviews the published results of such experiments critically, one should keep in mind all inherent limitations or assumptions which will tend to reduce the accuracy of their results. For example, the experimental errors introduced in the measurements of pressure in the 0.1 to 10 Torr range, of all flow rates (properly reduced to $\mathrm{cm}^{3}$ $\sec ^{1}$ N.T.P. or particles $\sec ^{-1}$ ), and of the geometry of the flow tube or reactor, and thereby the elapsed time-are likely to result in a minimum probable error of about $10 \%$ in the resultant rate constant. Next, major uncertainties arise from the oversimplification of the gas flow and from uncontrolled side reaction. Thus, for relatively slow reactions, concurrent surface recombination is always a serious problem; and for very fast reactions whose rate often can not be reduced by lowering reactant concentrations because of detector sensitivity, the flow velocity is likely to be high $\left(0.2\right.$ to $\left.1 \times 10^{4} \mathrm{~cm} \mathrm{sec}^{-1}\right)$ which complicates the reactant mixing problem, impedes the establishment of Poijeuille flow, and introduces axial pressure gradients. Probable errors of $10 \%$ due to these causes would seem to be conservative estimates in most cases. Finally, there are the errors associated with the method of detection. These are particularly serious when the absolute 
concentration of a reactive species must be known as in the calculation of bimolecular rate constants for the reaction involving two such molecules. In such cases, uncertainties in the optical or e。s.r.absorption coefficient, discrimination effects in mass spectrometric analysis, unknown detection efficiency and diffusion effects in probe calorimeters, and titration errors (especially overtitration) in chemiluminescent titrations, will add further errors which will usually amount to at least 10 to $20 \%$. It is clear, of course, that in any one series of measurements most of these errors will tend to remain fairly constant, and that therefore the average deviation from the mean in such a series is likely to be much smaller than the true probable error. This rather obvious reminder of the difference between precision and accuracy would seem to be out of place in such a review, were it not for the alarming rise in the claimed accuracy of many reported kinetic parameters. Thus, claims of a probable error (single standard deviation) in a rate constant of less than about $\pm 15 \%$ should in most cases be disregarded. As an example, one may cite one of the most easily measured rate constants by dischargeflow techniques, the recombination rate constant for $\mathrm{O}+\mathrm{NO}+\mathrm{O}_{2} \rightarrow \mathrm{NO}_{2}+\mathrm{O}_{2}-$ which is not a subject of this review - for which six separate investigations have reported values of $5.1,5.1,6.0,6.0,7.6$, and $8.0 \times 10^{-32} \mathrm{~cm}^{6}$ molecule $\mathrm{sec}^{-1}$, even though this is a pseudo first order process in which the concentrations of NO and $0_{2}$ are easily measured and remain constant and that of 0 therefore need not be known in absolute magnitude.

II. Review of Recent Rate Data.

The writing of this review was much aided by other recent summaries, especially by the excellent evaluation of kinetic rate data of Schofield (3) and by other review articles $(4,5,6)$. Reactions will be discussed in the approximate order of this author's earlier review (1), beginning with reactions of $H$, followed by $\mathrm{OH}, \mathrm{HO}_{2}, \mathrm{H}_{2}$, and $\mathrm{H}_{2} \mathrm{O}$, and ending with a few reactions of $\mathrm{CO}_{2}, \mathrm{~N}_{2} \mathrm{O}, \mathrm{CH}_{4}$, and of Na. Molecular units $\left(\mathrm{cm}^{3}\right.$ molecule $\mathrm{sec}^{-1}$ or $\mathrm{cm}^{6}$ molecule $\mathrm{sec}^{-1}$ ) will be used 
throughout, and should be assumed to apply when not specified. Specific rate constants are reported, i.e. for the reaction

$2 A \rightarrow B+C, k \equiv-1 / 2 \frac{d[A]}{d t} /[A]^{2}=\frac{d[B]}{d t} /[A]^{2}$ or for

$\left.2 \mathrm{~A}+\mathrm{M} \rightarrow \mathrm{A}_{2}+\mathrm{M}, \mathrm{k} \equiv-1 / 2 \frac{\mathrm{d}[\mathrm{A}]}{\mathrm{dt}} /[\mathrm{A}]^{2}[\mathrm{M}]=\frac{\mathrm{d}[\mathrm{A}}{\mathrm{dt}}\right] /[\mathrm{A}]^{2}[\mathrm{M}]$.

For each reaction, the energy change at absolute zero temperature, $\Delta \mathrm{E}_{\mathrm{O}}^{\mathrm{O}}$, will be given in units of $\mathrm{kcal}$ mole $\mathrm{e}^{-1}$, based on thermochemical data from the JANAF tables (7). Where this author is unaware of new work since his earlier review, that recommended value will be repeated without discussion for increased usefulness. Lastly, apologies are again in order for possible crimes of omission or commission.

A. Reactions of H-atoms

1. $\mathrm{H}+\mathrm{H}+\mathrm{M} \rightarrow \mathrm{H}_{2}+\mathrm{M}, \Delta \mathrm{E}_{\mathrm{o}}^{\mathrm{O}}=-103.26$

This reaction is not of aeronomic interest. It continues to be studied over a wide temperature range, because it is the most important test case of theory and experiment of atom recombination. Larkir. and Thrush (8) studied the $\mathrm{T}$ dependence $\left(213\right.$ to $\left.349^{\circ} \mathrm{K}\right)$ for $\mathrm{M}=\mathrm{Ar}$ and found $\mathrm{k}=1.2 \times 10^{-32}(273 / \mathrm{T})^{0.7}$, in fairly good agreement with the theory of Benson and Fueno (9), although the latter predicts a weaker $T$ dependence $\left(\sim \underline{T}^{-0.3}\right.$ for a Lennard-Jones potential for $H+H$ collision complexes).

The extensive work at high $\mathrm{T}$ by shock tube techniques can not be reviewed here. Sutton (10) finds a $\mathrm{T}^{-1}$ dependence between 2800 and $4500^{\circ} \mathrm{K}$ for $\mathrm{M}=\mathrm{H}_{2}$, and his $k$ extrapolates well to discharge-flow data near $300^{\circ} \mathrm{K}$. His $\mathrm{k}$ for $\mathrm{M}=\mathrm{H}$ is about ten times larger. Hurle (11) is in good agreement with Sutton for $M=H_{2}$, but reports a very much larger $k$ for $M=H$, with a very large negative $T$ dependence, $\mathrm{T}^{-7}$, between 4000 and $6000^{\circ} \mathrm{K}$. Such a value is clearly not extrapolatable to $300^{\circ} \mathrm{K}$, and Hurle is reported to have seen $\mathrm{k}$ come to maximum value near $3000^{\circ} \mathrm{K}$ and to appear to decrease again at lower $\mathrm{T}$ (12). Rosenfeld (12) has suggested an explanation for this interesting observation. More experimental work is needed, especially in an intermediate $T$ range. Although there is qualitative 
agreement on the relative efficiency of different $M, 1 . e \cdot A r<\mathrm{N}_{2}<\mathrm{H}_{2} \mathrm{O}<\mathrm{H} 2<\mathrm{H}$, there remain wide discrepancies in their exact magnitude.

$$
\text { 2. } \mathrm{H}+\mathrm{O}_{2}+\mathrm{M}+\mathrm{HO}_{2}+\mathrm{M} \quad \Delta \mathrm{E}_{\mathrm{O}}^{\mathrm{O}}=-45.9
$$

Two studies near $300^{\circ} \mathrm{K}$, one using chemiluminescent (13) and the other probe (14) detection have shown this to be a "normal" three-body atom-molecule recombination with a $k$ of $3 \pm 1 \times 10^{-32}(M=A r)$ and a ratio of about 20 for $\mathrm{k}^{\mathrm{H}} 2^{\mathrm{O}}: \mathrm{k}$ Ar From the M-effect on the second explosion limit of $\mathrm{H}_{2}-\mathrm{O}_{2}$ explosions near $800^{\circ} \mathrm{K}$, similar relative M-efficiences are obtained which place He and $\mathrm{O}_{2}$ near $\mathrm{Ar}, \mathrm{N}_{2} 1.5$ to 2 times larger, $\mathrm{H}_{2} 3$ times 1arger. Schofield (3) combined most available rate data to obtain $k=3 \times 10^{-32}(273 / \mathrm{T})^{1.3}$ which is likely to be approximately correct although the $\mathrm{T}^{-1.3}$ dependence is weaker than that of several similar recombinations.

$$
\text { 3. } \mathrm{H}+\mathrm{O}_{2} \rightarrow \mathrm{OH}+\mathrm{O} \quad \Delta \mathrm{E}_{\mathrm{o}}^{\mathrm{O}}=16.63
$$

The reaction is sufficiently endothermic to be of no direct importance. There is no experimental information on the interesting possibility of a forward reaction with $0_{2}, x^{3} \Sigma_{g}^{-}, v^{\prime \prime} \geq 4$ or with $0_{2}, a^{1} \Delta_{g}^{+}$or $b^{1} \Sigma_{g}^{+}$From the very large $k$ of the reverse reaction, $5 \pm 2 \times 10^{-11},(1)$, and the equilibrium constant, 21 exp $(16.8 / \mathrm{RT})$, a value of $1 \times 10^{-9} \mathrm{exp}(-16.8 / \mathrm{RT})$ is obtained if the reverse reaction $\mathrm{k}$ is assumed to be $\mathrm{T}$ independent. If the reverse reaction produces substantial vibrational excitation in $0_{2}$, the above "thermal" $\mathrm{k}$ would be too large The very large pre-exponential factor indirectly supports such a possibility.

$$
\text { 4. } \mathrm{H}+\mathrm{NO}+\mathrm{M} \rightarrow \mathrm{HNO}+\mathrm{M} \quad \Delta \mathrm{E}_{\mathrm{O}}^{\mathrm{O}}=-48.6
$$

Further work on this reaction since the last review included measurement of $k$ at $293^{\circ} \mathrm{K}$ for $\operatorname{six} \mathrm{M}$ as well as measurement of the relative $M$ effect in the concurrent chemiluminescent reaction to form $\mathrm{HNO}$ ( (15). For $\mathrm{M}=\mathrm{H}_{2}, \mathrm{k}$ is now found to be $5.7 \times 10^{-32}$, compared to $3.8 \times 10^{-32}$ in the earlier work of the same laboratory (16), and the relative efficiency of $M$ in the recombination, normalized to $\mathrm{M}=\mathrm{H}_{2}$ are: $\mathrm{He}-0.47, \mathrm{Ar}-0.54, \mathrm{CO}_{2}-1.1, \mathrm{~N}_{2} \mathrm{O}-1.2, \mathrm{SF}_{6}-1.9, \mathrm{H}_{2} \mathrm{O}-3.3$. The formation of HNO* was found to depend on $M$ in a similar manner. The further bimolecular reaction, $2 \mathrm{HNO} \rightarrow \mathrm{N}_{2} \mathrm{O}+\mathrm{H}_{2} \mathrm{O}$ was investigated by Clyne (17) who placed 
a lower limit of $0.5 \times 10^{-16}$ on its rate constant, and by Kohout and Lampe (18) who find $k=6.7 \pm 10^{-16}$ in a photolysis mass spectrometer study。

$$
\text { 5. } \mathrm{H}+\mathrm{NO}_{2} \rightarrow \mathrm{OH}+\mathrm{NO} \quad \Delta \mathrm{E}_{\mathrm{O}}^{\mathrm{o}}=-29.5
$$

No new work is available. The direct measurement of Phillips and Schiff (19) at $300^{\circ} \mathrm{K}$ gave $4.8 \pm 0.5 \times 10^{-11}$, and an indirect one by Rosser and Wise (20) gave much the same value near $500^{\circ} \mathrm{K}$. The latter value was misread by Schofield (3) who reported it as $2 \times 10^{-9}$. Further unpublished work at this author"s former laboratory has confirmed the earlier conclusion that there is very little if any vibrationally excited $\mathrm{OH}$ formed in the reaction.

$$
\text { 6. } \mathrm{H}+\mathrm{O}_{3} \rightarrow \mathrm{OH}+\mathrm{O}_{2} \quad \Delta \mathrm{E}_{\mathrm{C}}^{\mathrm{O}}=-7.1
$$

This reaction was extensively discussed in the earlier review (1). No new data are available on its rate constant, $2.6+0.5 \times 10^{-11}$ at $300^{\circ} \mathrm{K}$ as reported by Phillips and Schiff (19). Further work in the author's former laboratory has confirmed the formation of vibrationally highly excited $\mathrm{OH}$ as a major reaction product and has provided information on its collisional deactivation by various added gases. Anlauf, Macdonald, and Polanyi (21) have recently studied the infrared chemiluminescence of this reaction at pressures down to $10^{-4}$ Torr under conditions where $\mathrm{OH}^{+}$would either reast or be deactivated to $\mathrm{v}^{\prime \prime}=0$ at the wall of the reactor. The infrared emission indizated a highly non-Boltzmann distribution of $\mathrm{OH}^{+}$with increasing populations up to $\mathrm{v}^{\prime \prime}=9$, the highest available level, and about 80 to $85 \%$ of all molecules in $v^{\prime \prime} \geq 4$ if the populations in $v^{\prime \prime}=0$ to 2 are estimated by extrapolation. This result is in good agreement with the earlier $u_{0} v$. absorption work (1) in which only molecules with $v^{\prime \prime}=0$ and 1 were observed. The various fates of $\mathrm{OH}^{\ddagger}$ as a result of radiation, physical quenching, or chemical reactions were presented in the earlier review. The detailed course of its reaction with $\mathrm{O}_{3}$ has been further clarified by DeMore (22) who showed that the reaction between $\mathrm{OH}^{\dagger}$ and $\mathrm{O}_{3}$ may produce $\mathrm{H}+2 \mathrm{O}_{2}$ via highly excited $\mathrm{HO}_{2}$ after a single collision rather than only by two successive collisional processes, i.e. 
$\mathrm{OH}^{\ddagger}+\mathrm{O}_{3} \rightarrow \mathrm{OH}+\mathrm{O}_{2}+0$, followed by $\mathrm{OH}+0 \rightarrow \mathrm{O}_{2}+\mathrm{H}(1)$. This helps explain why the yield of $\mathrm{OH}, \mathrm{v}^{\prime \prime}=0$, does not increase strongly when very small concentrations of $\mathrm{H}$ are reacted with excess $0_{3}$.

$$
\text { 7. } \mathrm{H}+\mathrm{OH} \rightarrow \mathrm{H}_{2}+\mathrm{O} \quad \Delta \mathrm{E}_{\mathrm{o}}^{\mathrm{o}}=-1.9
$$

This rate constant is best obtained from its much studied reverse reaction for which three new values have been reported since the last review: $7 \times 10^{-11} \exp (-10.2 / \mathrm{RT})(23), 2 \times 10^{-11} \exp (9.2 / \mathrm{RT})(24)$, and $8 \times 10^{-11} \exp (-10.2 / \mathrm{RT})$ (25) Combined with the equilibrium constant, $k=0.44 \exp (1.87 / R T)$, and using the larger activation energy, one obtains $3 \times 10^{-11} \exp (8.3 / \mathrm{RT})$ which, although differing fairly substantially from the earlier recommended expression (1), does not yield very different rate constants near $300^{\circ} \mathrm{K}$.
8. $\mathrm{H}+\mathrm{HO}_{2} \rightarrow 2 \mathrm{OH}$
$\Delta \mathrm{E}_{\mathrm{O}}^{\mathrm{O}}=-38.8$
$8^{\prime} \cdot \mathrm{H}+\mathrm{HO}_{2} \rightarrow \mathrm{H}_{2}+\mathrm{O}_{2}$
$\Delta E_{o}^{\circ}=-57.3$

No new work is available. The earlier rough estimates of $k_{8} \geq 3 \times 10^{-12}$ stand (1).

B. Reactions of $\mathrm{OH}$.

$$
\text { 9. } 2 \mathrm{OH} \rightarrow \mathrm{H}_{2} \mathrm{O}+\mathrm{O} \quad \Delta \mathrm{E}_{\mathrm{o}}^{\mathrm{O}}=-16.7
$$

Since the earlier work (1) which reported $1.4 \pm 0.3 \times 10^{-12}$ at $300^{\circ} \mathrm{K}$ (the quoted $2.8 \times 10^{-12}$ referred to $-d[\mathrm{OH}] / d t=k[\mathrm{OH}]^{2}$, i.e. twice the specific rate constant) several other values have been published. Westenberg and deHaas (26) found $2 \pm 0.6 \times 10^{-12}$ by a similar method except for e.s.r. detection, and later work in the same laboratory (27) led to $2.6 \pm 0.25 \times 10^{-12}$. (The stated errors are single standard deviations calculated from the published data). Wilson and 0'Donovan (28) recently re-analyzed Herron's (29) data on the $\mathrm{CO}+\mathrm{OH}$ reaction and calculated $1.1 \pm 0.1 \times 10^{-12}$ for the $\mathrm{OH}+\mathrm{OH}$ reaction. They then performed similar experiments which yielded $2.1 \pm 0.1 \times 10^{-12}$, but rejected both 
in favor of their earlier $2.6 \pm 0.25 \times 10^{-12}$ (28). Several of these authors err in claiming excessive accuracy as discussed in the introduction, $i . e$. they simply report the average deviation from the mean of their calculated values, which is sometimes as low as $\pm 3 \%$. It is difficult to assess which of the two principal measurements, $1.4 \pm 0.3 \times 10^{-12}$ by $u . v \circ$ or $2.6 \pm 0.25 \times 10^{-12}$ by e.s.r. absorption, is more reliable. Experimentally, the $u_{\circ} v_{\circ}$ value has a slight edge, because it averages $\mathrm{OH}$ over a shorter distance along the flow tube, permits its measurement closer to the mixing point where $\mathrm{OH}$ is produced, and uses a better mixing device for the parent $\mathrm{H}+\mathrm{NO}_{2}$ reaction. The $\mathrm{u}_{\circ} \mathrm{v}$ 。 method was also used to measure the oscillator strength of the pertinent electronic transition, ${ }^{2} \Sigma^{+}-2 \pi$, and a result $f_{0,0}=7.1 \pm 1.0 \times 10^{-4}$ was obtained (30) in good agreement with the best direct measurement of the radiative 1 ffetime (31) which yields $8.0 \pm 0.8 \times 10^{-4}$. The effect of adopting the slightly higher $f$ would be a proportional decrease in all $\mathrm{OH}$ concentrations and an increase of $\mathrm{k}$ from 1.4 to $1.6 \pm 0.3 \times 10^{-12}$. The higher e.s.r. value, on the other hand, is supported by measurement of the ratio $\left[0_{2}\right]\left[\mathrm{CO}_{2}\right]_{\infty}$ at large reaction times when the $\mathrm{OH}+\mathrm{CO}$ reaction occurs concurrently, even though this support is predicated on the correctness of the $\mathrm{OH}+\mathrm{CO}$ rate constant. Very likely, the correct $\mathrm{k}$ will lie somewhere between 1.4 and $2.6 \times 10^{-11}$, but exaggerated claims of high accuracy should be disregarded.
10. $\mathrm{OH}+\mathrm{O} \rightarrow \mathrm{O}_{2}+\mathrm{H}$
$\Delta E_{0}^{o}=-16.6$

No further work is available. The earlier value of $5 \pm 2 \times 10^{-11}$ at $300^{\circ} \mathrm{K}$ stands.

$$
\text { 11. } \mathrm{OH}+\mathrm{O}_{3} \rightarrow \mathrm{HO}_{2}+\mathrm{O}_{2} \quad \Delta \mathrm{E}_{\mathrm{o}}^{\circ}=-38.3
$$

DeMore's recent photolysis work $(22,32)$ supports the earlier conclusion (1) that ground-state $\mathrm{OH}$ does not react rapidly with $0_{3}\left(k \leq 5 \times 10^{-13}\right)$ whereas excited $\mathrm{OH}$ from the $\mathrm{H}+\mathrm{O}_{3}$ reaction does so. No direct proof is available for the often invoked chain decomposition of $\mathrm{O}_{3}$ by this reaction followed by $\mathrm{HO}_{2}+\mathrm{O}_{3} \rightarrow \mathrm{OH}+2 \mathrm{O}_{2}$, and such a scheme should not be postulated without proof. With highly excited $\mathrm{OH}^{+}$, the reaction proceeds to give $\mathrm{H}+2 \mathrm{O}_{2}$ as previously 
discussed.

$$
\text { 12. } \mathrm{OH}+\mathrm{HO}_{2} \rightarrow \mathrm{H}_{2} \mathrm{O}+\mathrm{O}_{2} \quad \Delta \mathrm{E}_{\mathrm{o}}^{\mathrm{o}}=-72.1
$$

The earlier recommendation of a fast reaction, $k \geq 10^{-11}$, on the basis of indirect information on $\mathrm{HO}_{2}$ production, still stands.

$$
\text { 13. } \mathrm{OH}+\mathrm{H}_{2} \rightarrow \mathrm{H}_{2} \mathrm{O}+\mathrm{H} \quad \Delta \mathrm{E}_{\mathrm{O}}^{\mathrm{O}}=-14.7
$$

Two new measurements of this rate constant at $300^{\circ} \mathrm{K}$ have been reported, both in good agreement with the earlier value of $7 \pm 2 \times 10^{-15}$ (1). Dixon-Lewis, Wilson, and Westenberg (27) find $6.5 \pm 0.5 \times 10^{-15}$ by $e_{\circ} s_{\circ} r$ and Greiner (33) $6.7 \pm 0.4 \times 10^{-15}$ by flash photolysis and kinetic spectroscopy Combined with flame and shock tube data, this value has led to several Arrhenius expressions for $\mathrm{k}$ such as $6.3 \times 10^{-11} \exp (-5.49 / \mathrm{RT})$ (3), $1 \times 10^{-10} \exp (-5.9 / \mathrm{RT})(1)$, and $3.8 \times 10^{-11} \exp (-5.2 / \mathrm{RT})$ (27) which are also in close agreement over the relevant $\mathrm{T}$ range.

C. Reaction of $\mathrm{HO}_{2}$

No new information is available for the reactions $0+\mathrm{HO}_{2} \rightarrow \mathrm{OH}+\mathrm{O}_{2}, \mathrm{k} \geq 10^{-11}$ (1) and $2 \mathrm{HO}_{2} \rightarrow \mathrm{H}_{2} \mathrm{O}_{2}+0_{2}, \mathrm{k}=1.5 \times 10^{-12}$ (specific rate constant) (1).

D. Reactions of $\mathrm{H}_{2}$

14. $0+\mathrm{H}_{2} \rightarrow \mathrm{OH}+\mathrm{H} \quad \Delta \mathrm{E}_{\mathrm{O}}^{\mathrm{O}}=+1.9$

Several new studies of this important reaction of ground-state oxygen, ${ }^{3} \mathrm{P}$, have been reported, as noted above in the discussion of the reverse reaction. The rate expressions are:

$7 \times 10^{-11} \exp (-10.2 / \mathrm{RT})(23), 2 \times 10^{-11} \exp (-9.2 \mathrm{RT})(24)$, and $8 \times 10^{-11} \exp (-10.2 / R T)(25)$. Combining the first two of these with the earlier $2 \times 10^{-11}(-9.4 / \mathrm{RT})(34)$, Schofield suggested $2.1 \times 10^{-11} \exp (-9.4 / \mathrm{RT})(3)$. The most recent of these investigations, by Westenberg and deHaas (25) who use the discharge-flow method and e.s.r. detection, also indicates deviations from an Arrhenius expression at the low $\mathrm{T}$ end of their range $\left(350^{\circ} \mathrm{K}\right)$ which may be due to tunnelling. The higher activation energy of $10.2 \mathrm{kcal}$ seems to be slightly 
preferable, and an expression $7 \times 10^{-11} \exp (-10.2 / \mathrm{RT})$ is recommended.

E. Reactions of $\mathrm{CO}$ and $\mathrm{CO}_{2}$

As additional species are brought in for consideration and review, the number of possible reactions increases exponentially. Only very few of these reactions will be discussed, however, partly because of low aeronomic interest and partly because of the paucity of laboratory data. Moreover, all reactions of excited states are discussed elsewhere.

$$
\text { 15. } \mathrm{OH}+\mathrm{CO} \rightarrow \mathrm{H}+\mathrm{CO}_{2} \quad \Delta \mathrm{E}_{\mathrm{o}}^{\mathrm{O}}=-24.4
$$

Three recent measurements near $300^{\circ} \mathrm{K}$ have shown that this reaction has a much smaller activation energy than heretofore believed. Thus, Westenberg and Fristrom (35) combined available kinetic data in 1964 to give the rate expression $1.2 \times 10^{-11} \exp (-7.7 / \mathrm{RT})$, based in part on incorrect early discharge work (36). Yet since then, all measurements have indicated that $\mathrm{E}<2 \mathrm{kcal}$. Herron (30) reported $8.5 \pm 3 \times 10^{-14}$ at $300^{\circ} \mathrm{K}$ and derived $1.5 \times 10^{-12}$ exp $(-1.7 / \mathrm{RT})$ by combination with explosion and flame data; Dixon-Lewis, Wilson, and Westenberg (28) obtained $1.9 \times 10^{-13}$ at $300^{\circ} \mathrm{K}$ and derived $5.0 \times 10^{-13} \mathrm{exp}(-0,6 / \mathrm{RT})$; Greiner (34) obtained $1.5 \times 10^{-13}$ at $300^{\circ} \mathrm{K}$; and Wilson and $0^{\prime}$ Donavan (29) also obtained $1.5 \times 10^{-13}$ although they prefer the somewhat higher $1.7 \times 10^{-13}$ based on the earlier measurement of reaction 9. A three parameter expression for this rate constant has also been proposed (28) but is surely not warranted in view of the large spread of nearly an order of magnitude in the high $\mathrm{T}$ data. A compromise of $9 \times 10^{-13} \exp (-1.0 / \mathrm{RT})$ is suggested, albeit without special evidence.

The reverse reaction is endothermic and therefore quite slow. Using the expression $2.3 \times 10^{-3} \exp (+24.7 / R T)$ for the equilibrium constant over the range 300 to $1000^{\circ} \mathrm{K}$, the reverse $\mathrm{k}$ is $4.0 \times 10^{-10} \exp (-25.7 / \mathrm{RT})$. At $1000^{\circ} \mathrm{K}$, the equilibrium constant is 620 which shows that the reverse reaction is not altogether negligible. 


$$
\text { 16. } 0+\mathrm{CO}+\mathrm{M}+\mathrm{CO}_{2}+\mathrm{M} \quad \Delta \mathrm{E}_{\mathrm{o}}^{\mathrm{O}}=-125.75
$$

Our understanding of this simple recombination reaction is still in a most unsatisfactory state. There Is general agreement that the reaction is at least two to three orders of magnitude slower than "normal" recombinations such as $0+N O+M$ or $\mathrm{H}+\mathrm{O}_{2}+\mathrm{M}$, and therefore difficult to study in low pressure flow systems. But there has been lack of agreement whether the process is of second or third order in the Torr pressure range, and whether it has a positive or negative $\mathrm{T}$ dependence. Clyne and Thrush (37) found no measurable reaction at $293^{\circ} \mathrm{K}$ at a total pressure of 2 Torr and CO partial pressure up to 0.5 Torr, and placed an upper limit of $8 \times 10^{-35}$ on the third order $k$. They also reported a second order chemiluminescent rate constant of $1 \times 10^{-17} \exp (-3.7 / \mathrm{RT})$ for $\mathrm{M}=0_{2}$, indicating small energy barrier. Mahan and Solo (38) claim the recombination to be second order to pressures as low as 0.2 Torr and report $k=1.6 \times 10^{-14} \exp (-4.0 / \mathrm{RT})$ for the overall reaction and $2 \times 10^{-13} \exp (-9.5 / \mathrm{RT})$ for the chemiluminescent reaction. The former value is almost four times as large as the above upper limit at 2 Torr and therefore inconsistent with it. Hartunian, Thompson, and Hewitt (39) studied only the chemiluminescent reaction in a glowdischarge shock tube and reported $1.6 \times 10^{-18} \exp (-2.5 / \mathrm{RT})$ in fair agreement with ref. 37 and in good agreement with a value $0.5 \times 10^{-18} \mathrm{exp}(-2.5 / \mathrm{RT})$ obtained by Myers and Bartle (40) from shock tube work near $3000^{\circ} \mathrm{K}$. Avramenko and Kolesnikova (41) also reported the overall reaction to be second order with $k=1.6 \times 10^{-13} \exp (-3.8 / \mathrm{RT})$, but this value gives much too high a $\mathrm{k}$ at $300^{\circ} \mathrm{K}$ and is in strong disagreement with a recent measurement by Mulcahy and Williams (42) whose measured $0+\mathrm{C} 0$ rate is 100 times slower than the above at $456^{\circ} \mathrm{K}$. In all, it seems likely that the reaction has a small energy barrier and is third order, in the few Torr pressure range, but a definitive experimental study has yet to be undertaken. 
17. $\mathrm{H}+\mathrm{N}_{2} \mathrm{O} \rightarrow \mathrm{OH}+\mathrm{N}_{2} \quad \Delta \mathrm{E}_{\mathrm{O}}^{\mathrm{O}}=-62.8$

The neutral chemistry of $\mathrm{N}_{2} \mathrm{O}$ is unlikely to be of much importance in aeronomy because all its reactions involve fairly large energy barriers. This is true of the reaction $0+\mathrm{N}_{2} \mathrm{O} \rightarrow 2 \mathrm{~N} 0$ whose energy of activation is near $25 \mathrm{kcal}$ and it also applies to this reaction although to a lesser extent. The $\mathrm{H}+\mathrm{N}_{2} \mathrm{O}$ reaction was investigated indirectly by Fenimore and Jones (43) at 1260 to $1780^{\circ} \mathrm{K}$ by flame probe methods. These authors reported $7 \times 10^{-10} \exp (-16.3 / R T)$, but this result was based on the high value of the activation energy for reaction 13 , and the rate expression should therefore now be changed to $1.3 \times 10^{-10} \exp (-11.3 / \mathrm{RT})$. This is in fair agreement with more recent measurements by Dixon-Lewis, Sutton, and Williams (44) whose k's indicate a similar activation energy of $10.1 \mathrm{kcal}$ but are smaller in magnitude. Schofield (3) suggests the rate expression $5 \times 10^{-11} \exp (-10.8 / \mathrm{RT})$ as a mean of the available data. Because of slowness of this and other $\mathrm{N}_{2} \mathrm{O}$ reactions and because of the low concentrations of reactants it seems clear that its photochemistry will be of much greater importance than the above collisional processes.

$$
\text { 18. } \mathrm{H}+\mathrm{CH}_{4} \rightarrow \mathrm{CH}_{3}+\mathrm{H}_{2} \quad \Delta \mathrm{E}_{\mathrm{o}}^{\mathrm{O}}=-2.8
$$

The above remarks are applicable here. With the exception of the reaction with $0,{ }^{1}$, which is not covered in this review, all other neutral reactions of $\mathrm{CH}_{4}$ of aeronomic applicability involve energy barriers and are likely to be slow compared with photoexcitation or dissociation. For the present reaction, the $\Delta E_{0}^{O}$ of $2.8 \mathrm{kcal}$ calculated from the JANAF tables should probably be replaced by a value of $-0.6 \mathrm{kcal}$ based on Golden, Walsh, and Benson's (45) value for the energy of formation of $\mathrm{CH}_{3}$. Twelve investigations of this reaction are cited in a recent review (4). Reported activation energies range from 4.5 to $15.1 \mathrm{kcal}$ and preexponential values from $10^{-14}$ to $5 \times 10^{-10}$, but there is much better agreement on the absolute value of $\mathrm{k}$ than is indicated by this large spread. Schofield (3) has combined the data of seven of these studies in an Arrhenius plot and reports 
$6.7 \times 10^{-11} \exp (-11.6 / \mathrm{RT})$ which indicates that the reaction is negligibly slow near near $300^{\circ} \mathrm{K}$ 。

$$
\text { 19. } \mathrm{OH}+\mathrm{CH}_{4} \rightarrow \mathrm{H}_{2} \mathrm{O}+\mathrm{CH}_{3} \quad \Delta \mathrm{E}_{\mathrm{O}}^{\mathrm{O}}=-17.6
$$

Similar considerations apply here regarding $\Delta \mathrm{E}_{\mathrm{o}}^{\mathrm{O}}$ which is more probably -15.4 in view of the recent work on $\mathrm{CH}_{3}$ (45). This reaction has been studied repeatedly by a variety of experimental methods, with reported activation energies ranging from 5.0 to $9.0 \mathrm{kcal}$. Schofield's (3) analysis of most available data yields $1.2 \times 10^{-10} \exp (-5.9 / \mathrm{RT})$. In view of the very rapid reaction of $0 \mathrm{H}$ with 0 , the steady-state $\mathrm{OH}$ concentration is probably very small, and the present reaction is of no importance.

$$
\text { 20. } \mathrm{CH}_{4}+\mathrm{O} \rightarrow \mathrm{CH}_{3}+\mathrm{OH} \quad \Delta \mathrm{E}_{\mathrm{o}}^{\mathrm{O}}=-0.9
$$

$\Delta \mathrm{E}_{\mathrm{o}}^{\mathrm{O}}$ is more probably $+1.3 \mathrm{kcal}$ (45). Several recent studies of this reaction over the $\mathrm{T}$ range 300 to $1000^{\circ} \mathrm{K}$ are in surprisingly good agreement. Thus, Schofield (3) summarized the available data by the rate expression $5.3 \times 10^{-11}$ exp $(-7.95 / R T)$, where the specific investigations ranged only from 6.9 to $8.7 \mathrm{kcal}$ in their activation energies. Since the time of that summary, two more studies have been published, both using discharge-flow e.s.r. methods: Brown and Thursh (46) obtain $1.2 \times 10^{-11} \exp (-7.7 / \mathrm{RT})$ and Westenberg and deHaas (25) report $2.8 \times 10^{-11} \exp (-8.7 / \mathrm{RT})$. The latter expression probably represents the most accurate work, and since it also covers a much larger $T$ range than the former, it is to be preferred. It should be remembered that in this rate constant the subsequent reaction of $\mathrm{CH}_{3}$ with excess 0 have been taken into account, $i_{\circ} e_{\text {。 the }}$ total 0 -atom decay rate constant is given by $4 \mathrm{k}$.

$$
\text { 21. } \mathrm{Na}+\mathrm{O}_{2}+\mathrm{M} \rightarrow \mathrm{NaO} \mathrm{O}_{2}+\mathrm{M}
$$

No value of $\Delta \mathrm{E}_{\mathrm{o}}^{\mathrm{O}}$ is given for this reaction, because $\mathrm{Na} \mathrm{O}_{2}(\mathrm{~g})$ is not listed in the JANAF tables. There exists a recent, indirect measurement of $\Delta \mathrm{E}_{\mathrm{o}}^{\mathrm{o}}$ by McEwan and Phillips (47) of $-65 \pm 3 \mathrm{kcal}$, based on the approach to equilibrium of the present reaction in $\mathrm{O}_{2}-$ rich $\mathrm{H}_{2}-\mathrm{O}_{2}-\mathrm{N}_{2}$ flames. Compared with the corresponding values of 
-45.9 for $\mathrm{HO}_{2}$, this seems unexpectedly high. These authors also report a value of $2.0 \times 10^{-35}$ for the rate constant, surprisingly independent of $\mathrm{T}$ over the range 1380 to $2030^{\circ} \mathrm{K}$. This is in fairly good agreement with an earlier measurement by Kaskan (48) of $0.8 \times 10^{-33}$ obtained from flame work at 1 atm pressure in which 1: the reaction order could not be established. Recently, the pressure dependence of this process was investigated by Carabetta and Kaskan (49) over the pressure range from 100 to 1520 Torr, and the third order dependence was verified. A rate constant of $0.83 \times 10^{-33}$ was reported near $1500^{\circ} \mathrm{K}$. With an assumed $\mathrm{T}^{-1}$ to -2 dependence this will lead to a range of 0.5 to $2.5 \times 10^{-32}$ near $300^{\circ} \mathrm{K}, 200$ to 1000 times smaller than similarly extrapolated results of Bawn and Evans (50) which are probably too large because of neglect of quenching of $\mathrm{Na},{ }^{2} \mathrm{P}$, by $\mathrm{N}_{2}$ as discussed by Blamont and Donahue (51). However, this discrepancy appears too wide to be bridged by correction of the diffusion flame data (50). The flame $k^{\prime}$ s are smaller than one would expect for a fully allowed three-body process involving a large atom and a moderately electronegative molecule, they show no $\mathrm{T}$ dependence over a fairly large range, and they lead to an unreasonably large bond energy. Additional work at low $\mathrm{T}$ is needed。

To this author's knowledge, no experimental data are available on the kinetics of the reaction $\mathrm{NaO}_{2}+\mathrm{O} \rightarrow \mathrm{NaO}+\mathrm{O}_{2}$ and $\mathrm{NaO}+\mathrm{O} \rightarrow \mathrm{Na}+\mathrm{O}_{2}$ If the recent $\mathrm{Na}-0_{2}$ bond strength of $65 \mathrm{kcal}$ is correct and the JANAF value of 71.2 for the Na-0 bond strength is accepted, the former process, is only about $6 \mathrm{kcal}$ exothermic and the latter $46.8 \mathrm{kcal}$, only $1.7 \mathrm{kcal}$ less than the excitation energy of $\mathrm{Na},{ }^{2} \mathrm{P}_{1 / 2}$. The many other exothermic reaction of Na-oxides with $\mathrm{H}$ or $\mathrm{OH}$ can not be discussed for lack of any laboratory information. 


\section{References}

(1) F。 Kaufman, Ann. de Geophys. 20, 106 (1964)

(2) Faraday Discussion 44 , in press

(3) K. Schofield, Planet. Space Sci. 15, 643 (1967)

(4) Tables of Bimolecular Gas Reactions, A. F。 Trotman-Dickenson and G. S. Milne, U. S. Dept. of Commerce NSRDS - NBS 9, 1967

(5) B. H. Mahan, Annual Rev. Phys。Chem。17, 173 (1966)

(6) S. W. Benson and W. B. deMore, Annual Rev. Phys. Chem。16, 397 (1965)

(7) JANAF Thermochemical Tables, U. S. Dept。 of Commerce, Nat1. Bur。Standards, PB 168370, $-1,-2,1965,66,67$.

(8) F。 S. Larkin and B. A. Thursh, 10th Symp。 (Int.) Combustion, p. 397, The Combustion Institute, Pittsburgh, Pa., 1965.

(9) S. W. Benson and T. Fueno, J. Chem。 Phys。 $\underline{36}, 1697$ (1962)

(10) E. A. Sutton, J. Chem。 Phys. 36, 2923 (1962)

(11) I. R. Hurle, 11th Symp. (Int.) Combustion, p. 827 The Combustion Institute, Pittsburgh, Pa。, 1967

(12) J. L. J. Rosenfeld, Faraday Discussion 44, in press

(13) M. A. A. Clyne and B. A. Thrush, Proc, Roy. Soc. A275, 559 (1963)

(14) F. S. Larkin and B. A. Thrush, Faraday Discussion 37, 112, (1964)

(15) D. B. Hartley and B. A. Thrush, Proc. Roy。 Soc. A297, 520, (1967)

(16) Mo A。 A. Clyne and B. A. Thrush, Faraday Discussion 33, 139, (1962)

(17) M. A. A. Clyne, 10th Symp. (Int。) Combustion, p.311, The Combustion Institute, Pittsburgh, Pa, 1965

(18) F. C. Kohout and F. W. Lampe, J. Chem. Phys. 46, 4075 (1967)

(19) L. F. Phillips and H. I. Schiff, J。Chem. Phys。 37, 1233 (1962)

(20) W. A. Rosser, Jr. and H. Wise, J. Phys. Chem. 65, 532 (1961)

(21) K. G. Anlauf, R. G. Macdonald, and J. C. Polanyi, Chem. Phys. Letters 1, 619 (1968). 
(22) W. B. DeMore, J. Chem. Phys。 46, 813; 47, 2777 (1967)

(23) E. L. Wong and A. E. Potter, J. Chem. Phys. 43, 3371 (1965)

(24) D. L. Ripley and W. C. Gardiner, Jr。, J。Chem。Phys。 44, 2285 (1966)

(25) A. A. Westenberg and No deHaas, J. Chem Phys. 46, 490; 47, 4241 (1967)

(26) A. A. Westenberg and N. DeHaas, J. Chem. Phys. 43, 1550 (1965)

(27) G. Dixon-Lewis, W。 E. Wilson, and A。A. Westenberg, J. Chem. Phys. 44, 2877 (1966)

(28) W. E. Wilson, Jr. and J. T. O'Donovan, J. Chem. Phys. 47, 5455 (1967)

(29) J. T. Herron, J. Chem. Phys. 45, 1854 (1966)

(30) D. M. Golden, F。 P. DelGreco, and F. Kaufman, J. Chem. Phys。 393034 (1963)

(31) R. G. Bennett and F. W. Dalby, J. Chem. Phys. 40, 1414 (1964)

(32) W. B. DeMore and O.F。 Raper, J. Chem。 Phys. 46, 2500 (1967)

(33) N. R. Greiner, J。 Chem. Phys。 46,2795 (1967)

(34) M. A. A. Clyne and Thrush, Proc。Roy.Soc. A275, 544 (1963); 9th Symp. (Int.) Combustion, p. 211, Academic Press, N. Y. 1963

(35) A. A. Westenberg and R. M. Fristrom, 10th Symp. (Int.) Combustion, p. 473, The Combustion Institute, Pittsburgh, $\mathrm{Pa} 。 1965$

(36) L. I. Avramenko and R。V。 Lorentso, Zhur。 Fiz,Khim. 24, 207 (1950)

(37) M. A. A. Clyne and B. A. Thrush, Proc. Roy. Soc. A269, 404 (1962); 9th Symp. (Int.) Combustion, p. 177, Academic Press, N. Y., 1963

(38) B. H. Mahan and R. B. Solo。 J. Chem。 Phys. 37, 2669 (1962)

(39) R. A. Hartunian. W. P. Thompson, and E. W. Hewitt, J. Chem. Phys. 44, 1765 (1966)

(40) B. F. Myers and E. R. Bartle, J. Chem. Phys. 471783 (1967)

(41) L. I. Avramenko and R. V. Kolesnikova, Izv。Akad. Nauk SSSR 1959, 1562; 1960, 561

(42) M. F. R. Mulcahy and D. Jo Williams, Trans. Faraday Soc. 64, 59 (1968)

(43) C. P. Fenimore and G. W. Jones, J. Phys. Chem. 63, 1154 (1959) 
(44) G. Dixon-Lewis, M. M. Sutton, and A. Williams 10th Symp. (Int.) Combustion, p. 495, The Combustion Institute, Pittsburgh, Pa. 1965; J. Chem. Soc. 1965, 5724

(45) D. M. Golden. R. Walsh, and S. W. Benson, J. Am. Chem. Soc. 87, 4053 (1965)

(46) J. M. Brown and B. A. Thrush, Trans. Faraday Soc. 63, 630 (1967)

(47) M. J. McEwan and L. F. Phillips. Trans. Faraday Soc. 621717 (1966)

(48) W. E. Kaskan, 10th Symp. (Int.) Combustion, p。41, The Combustion Institute, Pittsburgh, Pa. 1965

(49) R. Carabetta and W。 E. Kaskan, J。Phys. Chem。, in press

(50) C. E. H. Bawn and A. G. Evans, Trans. Faraday Soc. 33, 1580 (1937)

(51) J. E. Blamont and T. M. Donahue, J. Geophys. Res. 69, 4093 (1964) 